See discussions, stats, and author profiles for this publication at: https://www.researchgate.net/publication/274093865

\title{
Development of egg PC/cholesterol/ $\alpha$-tocopherol liposomes with ionic gradients to deliver ropivacaine
}

Article in Journal of Liposome Research · March 2015

DOI: 10.3109/08982104.2015.1022555 · Source: PubMed

\section{CITATIONS}

7

7 authors, including:

Camila Morais Gonçalves da Silva

Anhanguera Educacional

45 PUBLICATIONS 403 CITATIONS

SEE PROFILE

Michelle Franz-Montan

University of Campinas

79 PUBLICATIONS 582 CITATIONS

SEE PROFILE
418

Leonardo Fraceto

São Paulo State University

267 PUBLICATIONS 3,506 CITATIONS

SEE PROFILE

Bruna Renata Casadei

Universidade Federal de São Paulo

25 PUBLICATIONS 91 CITATIONS

SEE PROFILE

Some of the authors of this publication are also working on these related projects:

Project Study of nanoparticles toxicity View project

Project Nanotechnology applied to agriculture View project 


\title{
Development of egg PC/cholesterol/a-tocopherol liposomes with ionic gradients to deliver ropivacaine
}

\author{
Camila Morais Gonçalves da Silva ${ }^{1}$, Leonardo Fernandes Fraceto ${ }^{1,2}$, Michelle Franz-Montan ${ }^{3}$, \\ Verônica Muniz Couto ${ }^{1}$, Bruna Renata Casadei ${ }^{1}$, Cíntia Maria Saia Cereda ${ }^{1}$, and Eneida de Paula ${ }^{1}$ \\ ${ }^{7}$ Department of Biochemistry and Tissue Biology, Institute of Biology, State University of Campinas, UNICAMP, Campinas, SP, Brazil, ${ }^{2}$ Department of \\ Environmental Engineering, São Paulo State University, Sorocaba, SP, Brazil, and ${ }^{3}$ Department of Physiological Sciences, Piracicaba Dental School, \\ State University of Campinas, UNICAMP, Piracicaba, SP, Brazil
}

\begin{abstract}
Context: Ropivacaine (RVC) is an aminoamide local anesthetic widely used in surgical procedures. Studies with RVC encapsulated in liposomes and complexed in cyclodextrins have shown good results, but in order to use RVC for lengthy procedures and during the postoperative period, a still more prolonged anesthetic effect is required.

Objective: This study therefore aimed to provide extended RVC release and increased upload using modified liposomes.

Materials and methods: Three types of vesicles were studied: (i) large multilamellar vesicle (LMV), (ii) large multivesicular vesicle (LMVV) and (iii) large unilamellar vesicle (LUV), prepared with egg phosphatidylcholine/cholesterol/ $\alpha$-tocopherol (4:3:0.07 mol\%) at $\mathrm{pH}$ 7.4. Ionic gradient liposomes (inside: $\mathrm{pH} 5.5, \mathrm{pH} 5.5+\left(\mathrm{NH}_{4}\right)_{2} \mathrm{SO}_{4}$ and $\left.\mathrm{pH} 7.4+\left(\mathrm{NH}_{4}\right)_{2} \mathrm{SO}_{4}\right)$ were prepared and showed improved RVC loading, compared to conventional liposomes (inside: $\mathrm{pH}$ 7.4).

Results and discussion: An high-performance liquid chromatography analytical method was validated for RVC quantification. The liposomes were characterized in terms of their size, zeta potential, polydispersion, morphology, RVC encapsulation efficiency $(\mathrm{EE}(\%))$ and in vitro RVC release. LMVV liposomes provided better performance than LMV or LUV. The best formulations were prepared using pH 5.5 ( $\mathrm{LMVV} 5.5_{\text {in }}$ ) or pH 7.4 with $250 \mathrm{mM}\left(\mathrm{NH}_{4}\right)_{2} \mathrm{SO}_{4}$ in the inner aqueous

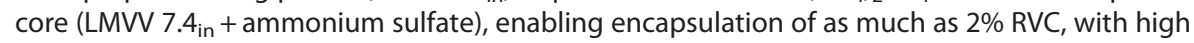
uptake $(\mathrm{EE}(\%) \sim 70 \%)$ and sustained release $(\sim 25 \mathrm{~h})$.

Conclusion: The encapsulation of RVC in ionic gradient liposomes significantly extended the duration of release of the anesthetic, showing that this strategy could be a viable means of promoting longer-term anesthesia during surgical procedures and during the postoperative period.
\end{abstract}

\section{Keywords}

Drug delivery, encapsulation efficiency, sustained release

\section{History}

Received 24 October 2014

Revised 7 February 2015

Accepted 20 February 2015

Published online 26 March 2015

\section{Introduction}

Ropivacaine (RVC), an amino-amide local anesthetic (LA), is extensively used due to its ability to target sensory rather than motor nerve fibers, and its lower cardiovascular and neurological toxicity, compared to bupivacaine (BVC), which is the LA most commonly used in surgical procedures (de Paula et al., 2010). RVC and BVC are homologs: the piperidine ring is propyl-substituted in the former and butyl-substituted in the latter, which explains their different partitioning coefficients (Strichartz \& Covino, 1990). Nonetheless, both anesthetics have similar onset times, potency and duration of action. The differential blockade of RVC is attributed to its synthesis as the $(S)$-enantiomer, while BVC is a racemate (Catterall \& Mackie, 2011).

Address for correspondence: Dr. Eneida de Paula, Department of Biochemistry and Tissue Biology, Institute of Biology, State University of Campinas (UNICAMP), P.O. Box 6109, CEP 13083-862, Campinas, SP, Brazil. Tel: +55 193521 6143. Fax: +55 193521 6185. E-mail: depaula@unicamp.br
Despite their efficacy, LAs are small molecules that are rapidly metabolized near to the injection site, which limits the duration of anesthesia (Grant, 2002; Grant \& Bansinath, 2001). RVC, for example, provides only $2-4 \mathrm{~h}$ of anesthetic effect (Lagan \& McLure, 2004). An approach that can be used to prolong anesthesia is the association of LAs with carriers such as liposomes, cyclodextrins and polymers, which enables retention of the drug close to the site of injection for a longer period and provides gradual release (Weiniger et al., 2010). The prolonged release also results in reduced toxicity of the compounds (de Paula et al., 2012).

Liposomes, the best-known drug carriers, are lipid vesicles with one or more lamellae and aqueous internal compartments, which can be prepared with lipids commonly found in biological membranes [mainly phospholipids, with or without cholesterol (chol)]. They are biocompatible and biodegradable (Torchilin, 2012; Wiles \& Nathanson, 2010). The arrangement of the lipids in bilayers creates a hydrophobic compartment (Torchilin, 2005), enabling liposomes to encapsulate nonpolar molecules, while hydrophilic drugs can be 
transported in the inner aqueous compartment(s). When developing lipid-based drug delivery systems, an important consideration is that the nature of the lipid (in terms of composition and size) determines the encapsulation efficiency and the drug release profile. Phosphatidylcholine (PC) is the lipid that is most widely used in liposome preparation, followed by chol (Samad et al., 2007), and the different properties of these substances play a crucial role in modulating the fluidity of the bilayer (Warren, 1987).

Since the development of the first liposomal formulation for LAs (Gesztes \& Mezei, 1988), other formulations with diverse lipid composition and vesicle types have been proposed and tested in animals (Boogaerts et al., 1995; Cereda et al., 2006; de Araújo et al., 2004; Grant et al., 1994, 1997, 2001; Yu et al., 2002) and humans (Boogaerts et al., 1994; Davidson et al., 2010; Franz-Montan et al., 2007; Lafont et al., 1996). Despite the success achieved with these conventional liposomes, modified vesicles have been proposed in order to increase LA encapsulation efficiency and prolong the duration of action, including liposomes with ionic gradients (Barenholz \& Haran, 1993, 1994; Grant et al., 2004; Mowat et al., 1996) (Figure 1).

Ionic gradient liposomes were described by Mowat et al. (1996), who prepared liposomes with an acidic inner aqueous compartment (containing $300 \mathrm{mM}$ citrate at $\mathrm{pH} 4.0$ ) and external $\mathrm{pH} 7.4$. They used $0.75 \%$ and $2 \% \mathrm{BVC}$ in their formulations. The large unilamellar vesicles (LUVs), composed of dioleoyl PC/chol (55:45 molar ratio), were able to upload BVC with high encapsulation efficiency (64-82\%), and sustained release (9-14 h) was obtained after intradermal administration in guinea pigs. Grant et al. (2004) incorporated BVC in large multivesicular vesicles (LMVVs) composed of hydrogenated soy $\mathrm{PC} / \mathrm{chol}$ (2:1 molar ratio) and containing $250 \mathrm{mM}$ ammonium sulfate in their aqueous inner compartments. At first, there was no difference between the inner and outer $\mathrm{pH}$ of the vesicles. However, after a while, ammonium ions left the interior of the vesicles in the form of ammonia, leaving protons that decrease the $\mathrm{pH}$, while sulfate anions could not permeate through the membrane. Highly soluble protonated BVC predominated at acid $\mathrm{pH}$, where sulfate acted as the counter-ion, allowing entrapment of large amounts of the anesthetic and hampering its leakage through the lipid bilayer. After intradermal administration in a human volunteer, up to 19,38 and $48 \mathrm{~h}$ of anesthesia were achieved with $0.5 \%, 1 \%$ and $2 \%$ BVC formulations, respectively. Recently, Cern et al. (2012) reported tests performed by the Barenholz group with 60 remotely-loaded drugs, and discussed the drugs that might be good candidates to benefit from the use of ionic gradient liposomal systems.

Although liposomes with ionic gradients have already been used for the encapsulation of LAs such as BVC, to our knowledge there have not been any studies concerning the similar encapsulation of RVC. In our previous work, $0.5 \%$ RVC was encapsulated into egg $\mathrm{PC} / \mathrm{chol} / \alpha$-tocopherol (4:3:0.07 molar ratio) liposomes, leading to a release time of $\sim 6 \mathrm{~h}$ that was 1.5 -fold longer than that of RVC in solution, but nevertheless still too short for long surgical procedures (de Araújo et al., 2008). The aim of this study was therefore to increase the encapsulation efficiency of RVC and prolong its release time in order to provide a formulation suitable for use during lengthy surgery and the postoperative period. For this, three different types of egg PC/chol/ $\alpha$-tocopherol (4:3:0.07 molar ratio) liposomes were prepared (LMVV, LUV and large multilamellar vesicles, LMVs) with ionic gradients ( $\mathrm{pH} 5.5$ inside, $\mathrm{pH} 7.4+250 \mathrm{mM}$ ammonium sulfate inside and $\mathrm{pH}$ $5.5+250 \mathrm{mM}$ ammonium sulfate inside). The results were compared with those obtained using conventional liposomes with no gradient (prepared with $\mathrm{pH} 7.4$ inside and outside), in order to identify the formulation that provided the best increase in $\mathrm{EE}(\%)$ and slow RVC release. This study should help to open perspectives for the clinical use of modified liposomal formulations of RVC.

\section{Materials and methods}

\section{Materials}

Egg phosphatidylcholine (EPC) was purchased from Avanti Lipids Inc. (Alabaster, AL). Ammonium molybdate, ascorbic acid, chol, Hepes, perchloric acid, sodium acetate, sulfuric acid, uranyl acetate, $\alpha$-tocopherol and 5-SASL were
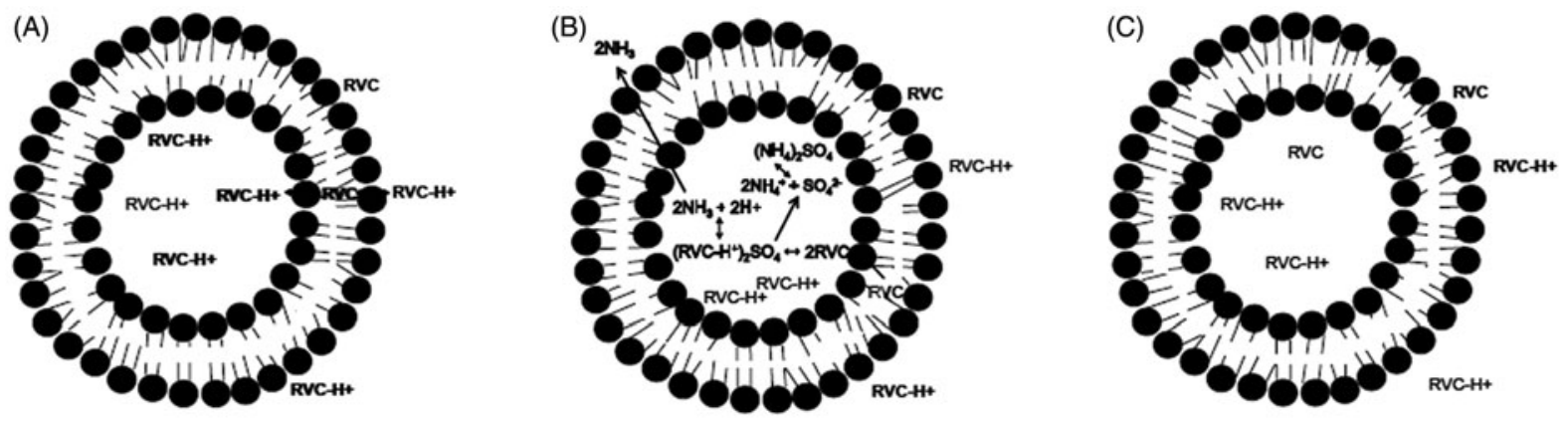

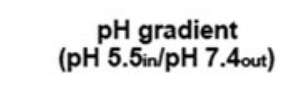

$50 \mathrm{mM}$ Hepes buffer $\mathrm{pH} 7.4$

$$
[\mathrm{RVC}-\mathrm{H}+]_{\text {in }} \gg[\mathrm{RVC}-\mathrm{H}+]_{\text {out }}
$$

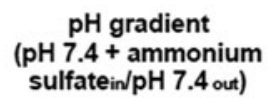

$50 \mathrm{mM}$ Hepes buffer $\mathrm{pH} 7.4$

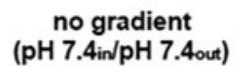

no gradient
(pH 7.4in/pH 7.4out)
$[\mathrm{RVC}-\mathrm{H}+]_{\text {in }}=[\mathrm{RVC}-\mathrm{H}+]_{\text {out }}$

Figure 1. Schematic representation of unilamellar lipid vesicles with $(\mathrm{A}, \mathrm{B})$ or without $(\mathrm{C})$ a transmembrane ionic gradient. The gradients were created by preparing the liposomes with an acidic internal $\mathrm{pH}(\mathrm{A})$ or with $250 \mathrm{mM}\left(\mathrm{NH}_{4}\right)_{2} \mathrm{SO}_{4}$ in the inner aqueous core (B), while the external vesicle medium was maintained at $\mathrm{pH} 7.4$. 
purchased from Sigma Chem. Co. (St. Louis, MO). Ammonium sulfate, dibasic sodium phosphate and monobasic sodium phosphate were acquired from Merck (São Paulo, Brazil). RVC hydrochloride was kindly donated by Cristália Indústria Química e Farmacêutica Ltda (Itapira, Brazil), and acetonitrile was purchased from JT Baker (Center Valley, PA).

\section{Methods}

\section{Preparation of ionic gradient liposomes}

Dry lipid films composed of egg PC/chol/ $\alpha$-tocopherol (4:3:0.07 molar ratio) were obtained after solvent evaporation under a flow of nitrogen. The last traces of solvent were removed under vacuum for at least $2 \mathrm{~h}$. LMV were produced by hydration, using four different solutions: (i) $50 \mathrm{mM}$ Hepes buffer at pH 7.4 (conventional, without ionic gradient); (ii) $50 \mathrm{mM}$ Hepes buffer at $\mathrm{pH} 7.4+250 \mathrm{mM}$ ammonium sulfate; (iii) $50 \mathrm{mM}$ sodium acetate buffer at $\mathrm{pH} 5.5$; and (iv) $50 \mathrm{mM}$ sodium acetate buffer at $\mathrm{pH} 5.5+250 \mathrm{mM}$ ammonium sulfate. The final lipid concentration was $15 \mathrm{mM}$ for all formulations. An aliquot of each LMV preparation was extruded 12 times, at $40 \mathrm{psi}$, through $400 \mathrm{~nm}$ polycarbonate membranes (Lipex Biomembranes Inc., Vancouver, Canada), at room temperature, to form LUVs (Cereda et al., 2004). Another aliquot of LMV was first extruded 12 times through a $100 \mathrm{~nm}$ polycarbonate membrane, at room temperature, after which the extruded vesicles were then submitted to 10 freeze-thaw agitation cycles (using liquid nitrogen and a thermostatic bath at $37^{\circ} \mathrm{C}$ ) to form LMVV (Cohen et al., 2012).

In order to produce the ionic gradients, the liposomes manufactured using methods (ii)-(iv) were centrifuged (Celano et al., 2004; Tu et al., 2010) at $120000 \mathrm{~g}$ (de Paula \& Schreier, 1995) for $2 \mathrm{~h}$ at $4{ }^{\circ} \mathrm{C}$, twice, and the pellets were suspended in $50 \mathrm{mM}$ Hepes buffer (pH 7.4). Active incorporation of the anesthetic was achieved by incubating the liposomes overnight with $2 \%$ RVC, under gentle agitation (SK 0330 Pro Shaker, Scilogex, Cambridge, UK), at room temperature. The final formulation, containing $15 \mathrm{mM}$ total lipids and $2 \%$ RVC $(64 \mathrm{mM})$ was stored under refrigeration for further use.

Phospholipid concentration was quantified by inorganic phosphorus assay (Chen et al., 1956), with modifications. Briefly, perchloric acid was added to liposome aliquots previously dried overnight. After $1 \mathrm{~h}$ at $180^{\circ} \mathrm{C}$, a molybdate in sulfuric acid solution plus reduction agent (ascorbic acid) were added to the tubes, agitated for $20 \mathrm{~min}$ in a $45^{\circ} \mathrm{C}$ water bath. The absorbance of the samples was read at $820 \mathrm{~nm}$. Cholesterol concentration was determined with an enzymatic/ colorimetric assay kit (\#743051, Laborclin, Pinhais, Brazil).

\section{Membrane organization}

Electron paramagnetic resonance (EPR) measurements were used to determine changes in the fluidity of LMV prepared with and without chol, as well as after RVC encapsulation. Spectra of the 5-doxyl-stearic acid (5-SASL) spin probe, incorporated into the bilayers at up to $1 \mathrm{~mol} \%$ of total lipids, were recorded using a Bruker ELEXSYS spectrometer (Bruker BioSpin $\mathrm{GmbH}$, Karlsruhe, Germany) operated at $9.7 \mathrm{GHz}$, at room temperature $\left(21 \pm 1{ }^{\circ} \mathrm{C}\right)$. For 5-SASL, whose long molecular axis is roughly parallel to the bilayer normal, the order parameter $(S)$ was calculated according to Schreier et al. (1978):

$$
S=\frac{A_{\|}+A^{\perp}}{\left[A_{z z}-\left(A_{x x}+A_{y y}\right) / 2\right]}
$$

where $A_{\|}$and $\mathrm{A}^{\perp}$ are the hyperfine splitting for the spin label's long molecular axis oriented parallel and perpendicular, respectively, to the external magnetic field (Schreier et al., 1978), and $A_{z z}$ ( 32 Gauss), $A_{y y}$ (6 Gauss) and $A_{x x}$ (6 Gauss) are the values of the principal components of the hyperfine tensor (Griffith \& Jost, 1976) in an oriented sample.

\section{Liposome characterization}

Determination of particle size, polydispersity index and zeta potential

Liposome size, polydispersity index (PDI) and zeta potential $(\mathrm{mV})$ were determined at $25^{\circ} \mathrm{C}$ by dynamic light scattering, employing a Zetasizer ZS-90 particle analyzer (Malvern Instruments, Malvern, UK) (de Araújo et al., 2008), before and after RVC encapsulation. To perform the measurements, the liposome suspensions were diluted with Milli-Q water (Elga LLC, Woodridge, IL) to a final concentration of $1 \mathrm{mM}$. Three samples were analyzed in triplicate.

\section{Liposome morphology}

The morphology of the liposomes was evaluated by transmission electron microscopy (TEM), using a LEO 906 microscope (Carl Zeiss Group, Oberkochen, Germany) operated at $80 \mathrm{kV}$. Aliquots $(50 \mu \mathrm{L})$ of the liposome suspensions were placed onto 200 mesh copper grids for $10 \mathrm{~s}$, and the excess liquid was removed with a filter paper. A solution of uranyl acetate $(2 \%)$ was then added dropwise to the grid, and a filter paper was used to remove the excess liquid. The samples were subsequently incubated for $4 \mathrm{~h}$ at room temperature, prior to microscopy analysis (Barbosa et al., 2013a).

\section{RVC encapsulation efficiency}

The encapsulation efficiency, $\mathrm{EE}(\%)$, of each liposomal suspension loaded with RVC was determined after ultrafiltration-centrifugation (4000 $\mathrm{g}$ for $20 \mathrm{~min}$ ) in a $10 \mathrm{kDa}$ regenerated cellulose Millex filtration device (Millipore, Bedford, MA) (Barbosa et al., 2013b). The RVC content in the filtrate was determined by high-performance liquid chromatography (HPLC) at $240 \mathrm{~nm}$. The encapsulation efficiency was calculated using Equation (2):

$$
\mathrm{EE}(\%)=\frac{\mathrm{RVC}_{\text {bound }}}{\mathrm{RVC}_{\text {total }}} \times 100
$$

where $\mathrm{RVC}_{\mathrm{bound}}$ refers to the amount of $\mathrm{RVC}$ encapsulated in the liposomes, and $\mathrm{RVC}_{\text {total }}$ corresponds to the initial (total) amount of anesthetic added to the formulation. $\mathrm{RVC}_{\mathrm{bound}}$ was determined as the difference between $\mathrm{RVC}_{\text {total }}$ and free $\mathrm{RVC}$ in the filtered fraction, determined by HPLC as described earlier.

\section{In vitro release assays}

In vitro release experiments were conducted at $25^{\circ} \mathrm{C}$ using a two-compartment dialysis system. Donor $(1 \mathrm{~mL}$, containing 
free or liposome-encapsulated RVC) and acceptor (containing $4 \mathrm{~mL}$ of $50 \mathrm{mM}$ Hepes buffer at $\mathrm{pH} 7.4$ ) compartments were separated by a cellulose membrane 12-14 kDa cutoff (Spectrum Laboratories, Inc., Rancho Dominguez, CA) (de Araújo et al., 2008). At regular intervals, $200 \mu \mathrm{L}$ aliquots were withdrawn from the acceptor compartment for quantification of RVC by HPLC at $240 \mathrm{~nm}$. The volume withdrawn was replaced with $50 \mathrm{mM}$ Hepes buffer ( $\mathrm{pH}$ 7.4).

\section{Validation of RVC analysis by HPLC}

HPLC was used to evaluate the encapsulation efficiency and the duration of release of RVC from the liposomes. The validation of the analytical methodology followed the guidelines of the International Conference on Harmonization of Technical Requirements for Registration of Pharmaceuticals for Human Use (ICH, 2005). The validation parameters determined were linearity, precision, accuracy, limit of detection, limit of quantification (LQ) and specificity. For this purpose, samples were analyzed on three consecutive days.

Samples were injected onto a Purospher Star RP 18E octadecylsilane $150 \mathrm{~mm} \times 4.6 \mathrm{~mm}$ column (Merck KGaA, Darmstadt, Germany), kept at $30^{\circ} \mathrm{C}$. A mobile phase of acetonitrile/pH 8.0 phosphate buffer $(60: 40, \mathrm{v} / \mathrm{v})$ was filtered and degassed prior to use. The flow rate was set to $1.2 \mathrm{~mL} / \mathrm{min}$, the injection volume was $30 \mu \mathrm{L}$ and all samples were previously filtered through a $0.22 \mu \mathrm{m}$ polyethersulfone membrane (Millipore, Bedford, MA). RVC was detected at $240 \mathrm{~nm}$ (Jonsson et al., 2000; Zuo et al., 2004).

\section{Linearity}

Linearity was measured using three calibration curves of peak area against RVC concentration, in the range $250-2500 \mu \mathrm{g} / \mathrm{mL}$, with six different concentration levels. The relative standard deviation (RSD) values were calculated for the slope and Y-intercept of the calibration curve.

\section{Precision and accuracy}

Precision and accuracy were calculated from the intra-day and between-day variability, at three concentration levels (1000, 2188 and $2500 \mu \mathrm{g} / \mathrm{mL}$ ), using three replicates. Accuracy was based on the difference between the mean calculated concentration and the nominal concentration, and precision was determined as the RSD.

\section{Limits of detection and quantification}

The limit of detection (LD) is defined as the smallest quantity of analyte able to be detected, but not necessarily quantified, in a sample under a given set of experimental conditions. The LQ is the smallest amount that can be quantified. To determine these parameters, a calibration curve was constructed using analyte concentrations in the range $250-2500 \mu \mathrm{g} / \mathrm{mL}$ (measured in triplicate on three successive days). The average areas of the nine peaks at each concentration were plotted as a function of concentration, and the results were treated using linear regression $(Y=a+b X)$. The values of the slope $(b)$ and the standard deviation (SD) of the Y-intercepts $(a)$ of the regression lines were used to calculate the LD and LQ (Cereda et al., 2013; Grillo et al., 2009):

$$
\begin{aligned}
& \mathrm{LD}=\frac{\mathrm{SD}(a) \times 3.3}{b}, \\
& \mathrm{LQ}=\frac{\operatorname{SD}(a) \times 10}{b} .
\end{aligned}
$$

\section{Specificity}

Analytical specificity is required so that measurements can be made successfully in the presence of other substances (such as impurities, matrix components and degradation products). In these tests, filtered aliquots of each type of liposome sample were injected onto the Purospher Star RP 18 E column, under the conditions described earlier.

\section{Statistical analysis}

The data were analyzed using the GraphPad Instat v.3.0 program (GraphPad Software, San Diego, CA). The unpaired $t$-test was used to evaluate the results obtained for diameter, PDI, zeta potential, EPR, and encapsulation efficiency, and one-way ANOVA with the Tukey-Kramer test was used to evaluate the data obtained from the dialysis experiments. Statistical significance was defined as $p<0.05$. The results obtained for the ionic gradient formulations were compared to those for conventional liposomes (without gradient).

\section{Results and discussion}

\section{Selection of the best liposome composition for maintaining the ionic gradient}

Previous studies of $\mathrm{pH}$ and ion-gradient liposomes have shown that membrane fluidity is an important parameter influencing the duration of the ionic gradient (Grant et al., 2004; Mowat et al., 1996). In order to assess the degree of membrane organization, spectral measurements were made of the 5-SASL spin probe embedded in the LMV, using EPR. The spectra (Figure 2) were used to determine the segmental order parameter $(S)$, as described earlier (Methods section). The $S$ parameter enables evaluation of membrane organization using a scale of $0-1$, with values close to unity indicative of a high degree of orientation of the lipid with respect to the bilayer normal (Schreier et al., 1978). The $S$ values were used to determine the ability of chol to modulate the lipid bilayer fluidity. As expected, the organization of the EPC LMVs was significantly increased in the presence of chol $(S=0.686 \pm 0.010$ for egg PC/ $\alpha$-tocopherol $(4: 0.07 \mathrm{~mol} \%)$, and $S=0.708 \pm 0.003$ for egg $\mathrm{PC} / \mathrm{chol} / \alpha$-tocopherol (4:3:0.07 mol\%); $p<0.05)$. The $S$ values found for egg PC and egg PC/chol $(4: 3 \mathrm{~mol} \%)$ membranes were in accordance with previously reported values of $S=0.65$ (de Paula \& Schreier, 1995) and $S=0.70$ (Cereda et al., 2013), respectively. Given these findings, it was decided to include chol in the liposome composition, to provide a less fluid membrane able to maintain the ionic gradient between the inside and outside of the vesicles. Similar results were obtained for LUV and LMVV (data not shown). 


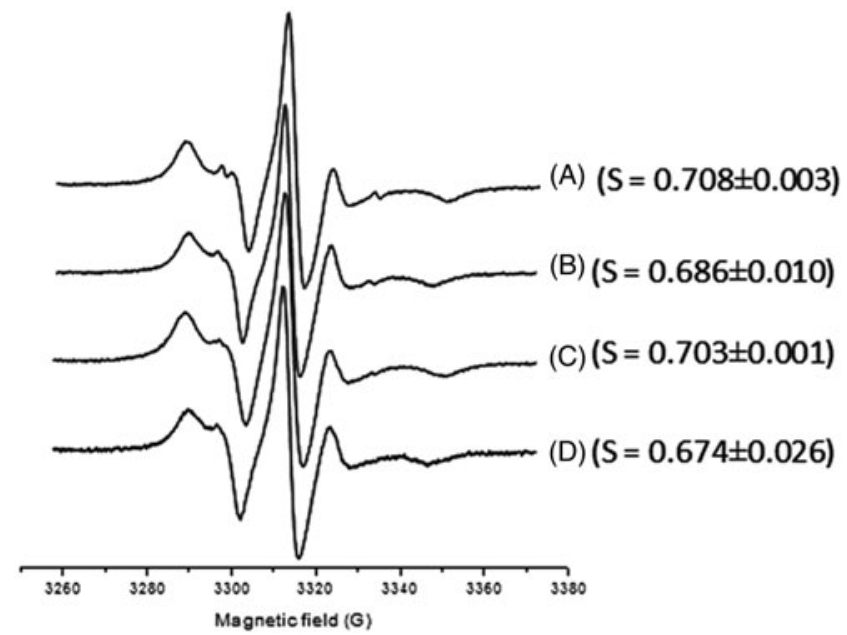

Figure 2. EPR spectra of 5-SASL incorporated (at $1 \mathrm{~mol} \%$ of total lipids) into the liposomes: (A) egg PC/chol/ $\alpha$-tocopherol (4:3:0.07 molar ratio) LMV 7.4 in ; (B) egg PC/ $\alpha$-tocopherol (4:0.07 molar ratio) LMV 7.4 in; (C) egg PC/chol/ $\alpha$-tocopherol (4:3:0.07 molar ratio) LMV $7.4_{\text {in }}+2 \%$ RVC; (D) egg PC/ $\alpha$-tocopherol (4:0.07 molar ratio) LMV 7.4 in $+2 \%$ RVC. The calculated segmental order parameter values ( $S$ values, see text) are given in the right-hand side of each spectrum.

Determination was made of the effect of RVC addition on the order parameters of the vesicles. The $S$ values were always slightly smaller in the presence of the anesthetic, with or without chol $(S=0.674 \pm 0.026$ for egg PC/ $\alpha$-tocopherol $(4: 0.07 \mathrm{~mol} \%)+2 \% \quad \mathrm{RVC}$, and $S=0.703 \pm$ 0.001 for egg $\mathrm{PC} / \mathrm{chol} / \alpha$-tocopherol $(4: 3: 0.07 \mathrm{~mol} \%)+2 \%$ $\mathrm{RVC})$. The value obtained for the vesicles with chol was significantly different to the value for the same formulation without RVC. Similar decreases in membrane organization have been observed for the partitioning of nine other LAs (de Paula \& Schreier, 1995), benzocaine (Pinto et al., 2000) and butamben (Cereda et al., 2013) into LMV of egg PC membranes, which provided strong evidence of RVC insertion into the lipid bilayer. Such insertion between the lipids causes bilayer disorganization near the region sensed by the 5-SASL probe.

\section{Validation of RVC analysis by HPLC}

In order to quantify RVC in the formulations, it was necessary to validate the HPLC methodology. The retention time of RVC was $3.8 \mathrm{~min}$, under the experimental conditions used. The calibration curve obtained by plotting RVC peak areas against concentrations in the range $250-2500 \mu \mathrm{g} / \mathrm{mL}$ was linear, with a correlation coefficient of 0.9991 . The values of the intercept and the slope were $-170.52 \pm 62.89$ and $1997.7 \pm 7.74$, respectively. The limits of detection and quantification were 0.09 and $0.31 \mu \mathrm{g} / \mathrm{mL}$, respectively. The accuracy of the technique was determined from the recovery of known added amounts of RVC. Satisfactory average recoveries were obtained, in the range 99.62-100.96\% (Table 1). Intra-day precision was evaluated at three different concentration levels, and intermediate precision was determined by analyzing the same solutions on three different days. The RSDs obtained $(<3.0 \%)$ indicated good precision of the procedure (Table 2 ).
Table 1. Accuracy studies for validation of the method for RVC analysis using HPLC.

\begin{tabular}{|c|c|c|c|}
\hline $\begin{array}{l}\text { RVC concentration } \\
\text { added }(\mu \mathrm{g} / \mathrm{mL})\end{array}$ & $\begin{array}{c}\text { RVC } \\
\text { concentration } \\
\text { found }(\mu \mathrm{g} / \mathrm{mL}) \\
\end{array}$ & $\begin{array}{c}\text { RVC } \\
\text { concentration found } \\
(\mu \mathrm{g} / \mathrm{mL}): \text { mean } \pm \mathrm{SD}\end{array}$ & $\begin{array}{l}\text { Recovery } \\
\text { mean }(\%)\end{array}$ \\
\hline \multicolumn{4}{|l|}{1000} \\
\hline Day 1 & $\begin{array}{r}967.86 \\
1017.64 \\
970.07\end{array}$ & $985.19 \pm 28.12$ & 99.62 \\
\hline Day 2 & $\begin{array}{r}1001.68 \\
1028.18 \\
983.94\end{array}$ & $1004.60 \pm 22.26$ & \\
\hline Day 3 & $\begin{array}{r}1018.39 \\
988.38 \\
989.34\end{array}$ & $998.70 \pm 17.06$ & \\
\hline \multicolumn{4}{|l|}{2188} \\
\hline Day 1 & $\begin{array}{l}2145.75 \\
2247.62 \\
2253.34\end{array}$ & $2215.57 \pm 60.53$ & 100.96 \\
\hline Day 2 & $\begin{array}{l}2245.98 \\
2254.19 \\
2184.39\end{array}$ & $2228.19 \pm 38.15$ & \\
\hline Day 3 & $\begin{array}{l}2153.23 \\
2210.02 \\
2181.63\end{array}$ & $2181.63 \pm 28.40$ & \\
\hline \multicolumn{4}{|l|}{2500} \\
\hline Day 1 & $\begin{array}{l}2447.13 \\
2454.00 \\
2466.40\end{array}$ & $2455.84 \pm 9.77$ & 99.67 \\
\hline Day 2 & $\begin{array}{l}2475.06 \\
2485.61 \\
2458.17\end{array}$ & $2472.95 \pm 13.84$ & \\
\hline Day 3 & $\begin{array}{l}2559.51 \\
2556.55 \\
2523.28\end{array}$ & $2546.45 \pm 20.12$ & \\
\hline
\end{tabular}

Table 2. Precision studies for validation of the method for ropivacaine analysis using HPLC.

\begin{tabular}{lcccc}
\hline $\begin{array}{l}\text { RVC concentration } \\
\text { added }(\mu \mathrm{g} / \mathrm{mL})\end{array}$ & $\begin{array}{c}\text { Day 1 } \\
\text { RSD }(\%)\end{array}$ & $\begin{array}{c}\text { Day 2 } \\
\text { RSD }(\%)\end{array}$ & $\begin{array}{c}\text { Day 3 } \\
\text { RSD (\%) }\end{array}$ & $\begin{array}{c}\text { Inter-day } \\
\text { RSD }(\%)\end{array}$ \\
\hline 1000 & 2.85 & 2.22 & 1.71 & 2.17 \\
2188 & 2.73 & 1.71 & 1.30 & 1.98 \\
2500 & 0.40 & 0.56 & 0.79 & 1.75 \\
\hline
\end{tabular}

No peaks were detected for blank samples (liposomes without RVC) at retention time of RVC, demonstrating that the technique was specific.

\section{Liposome characterization}

Dynamic light scattering was used to determine the particle size, PDI and zeta potential of the LMV, LMVV and LUV samples, with or without RVC (Table 3). Among the three types of liposomes studied, LMV showed the largest diameter and greatest polydispersity $(\sim 1.0)$, followed by LMVV and LUV, irrespective of the presence of an ionic gradient and/or RVC. The zeta potentials were always negative $(-50$ to $-7 \mathrm{mV}$ ), but became slightly less negative ( -33 to $-7 \mathrm{mV}$ ) after the addition of RVC. This effect was particularly evident for LMV, and since RVC is mainly protonated at $\mathrm{pH} 7.4$ $\left(\mathrm{p} K_{\mathrm{a}}=8.1\right.$, Lagan \& McLure, 2004), its interaction with the polar head groups of the egg PC lipids could explain the lower external electric charges observed after RVC addition (Table 3). Similar observations were reported for the 
Table 3. Mean diameter, polydispersity and zeta potential values for egg PC/chol/ $\alpha$-tocopherol (4:3:0.07 molar ratio) LMV, LMVV and LUV, with ionic gradients (formulations $\mathrm{pH} 7.4_{\text {in }}+250 \mathrm{mM}$ ammonium sulfate, $\mathrm{pH} 5.5_{\text {in }}$ and $\mathrm{pH} 5.5_{\text {in }}+250 \mathrm{mM}$ ammonium sulfate), and for the conventional formulation ( $\mathrm{pH} 7.4_{\text {in }}$ ), before and after encapsulation of $2 \% \mathrm{RVC}$ and encapsulation efficiency (\%EE) values for RVC in these formulations.

\begin{tabular}{|c|c|c|c|c|c|c|c|}
\hline Vesicles & \multicolumn{3}{|c|}{ Without RVC } & \multicolumn{4}{|c|}{$2 \% \mathrm{RVC}$} \\
\hline LMV $7.4_{\text {in }}+$ ammonium sulfate & $901.8 \pm 12.7$ & $0.7 \pm 0.0$ & $-46.5 \pm 1.5$ & $1564.0 \pm 120.2^{\mathrm{a}}$ & $0.9 \pm 0.1^{\mathrm{a}}$ & $-24.5 \pm 0.9^{\mathrm{a}}$ & $19.4 \pm 0.3$ \\
\hline LMV $5.5_{\text {in }}$ & $1153.5 \pm 31.8$ & $1.0 \pm 0.0$ & $-40.3 \pm 0.0$ & $1945.0 \pm 281.4^{\mathrm{a}}$ & $0.9 \pm 0.0^{\mathrm{a}}$ & $-29.3 \pm 0.2^{\mathrm{a}}$ & $17.8 \pm 0.4$ \\
\hline LMV $5.5_{\text {in }}+$ ammonium sulfate & $2121.5 \pm 140.7$ & $1.0 \pm 0.0$ & $-32.8 \pm 1.4$ & $1453.0 \pm 220.6^{\mathrm{a}}$ & $0.9 \pm 0.0^{\mathrm{a}}$ & $-21.4 \pm 0.4^{\mathrm{a}}$ & $22.5 \pm 0.5^{\mathrm{b}}$ \\
\hline LMVV $5.5_{\text {in }}+$ ammonium sulfate & $935.0 \pm 175.3$ & $0.7 \pm 0.0$ & $-37.9 \pm 2.7$ & $835.7 \pm 5.7$ & $0.8 \pm 0.0^{\mathrm{a}}$ & $-7.7 \pm 0.6$ & $63.0 \pm 4.0$ \\
\hline LUV $7.4_{\text {in }}$ & $662.4 \pm 1.3$ & $0.2 \pm 0.0$ & $-14.7 \pm 1.4$ & $588.0 \pm 65.5$ & $0.3 \pm 0.0^{\mathrm{a}}$ & $-19.2 \pm 0.6^{\mathrm{a}}$ & $30.8 \pm 0.5$ \\
\hline LUV $7.4_{\text {in }}+$ ammonium sulfate & $650.1 \pm 56.3$ & $0.2 \pm 0.0$ & $-46.2 \pm 1.0$ & $633.7 \pm 33.9$ & $0.3 \pm 0.0^{\mathrm{a}}$ & $-19.7 \pm 1.1^{\mathrm{a}}$ & $30.0 \pm 0.3$ \\
\hline LUV $5.5_{\text {in }}$ & $582.2 \pm 3.5$ & $0.2 \pm 0.0$ & $-20.7 \pm 2.0$ & $689.4 \pm 7.4^{\mathrm{a}}$ & $0.3 \pm 0.0^{\mathrm{a}}$ & $-22.0 \pm 0.9$ & $31.6 \pm 0.3$ \\
\hline LUV $5.5_{\text {in }}+$ ammonium sulfate & $407.2 \pm 28.4$ & $0.2 \pm 0.0$ & $-22.7 \pm 0.3$ & $527.0 \pm 8.8^{\mathrm{a}}$ & $0.3 \pm 0.0^{\mathrm{a}}$ & $-26.8 \pm 0.1^{\mathrm{a}}$ & $23.8 \pm 0.2$ \\
\hline
\end{tabular}

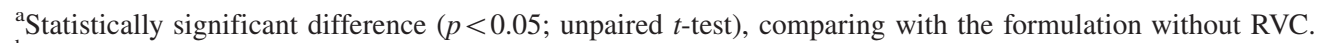

${ }^{\mathrm{b}}$ Statistically significant difference ( $p<0.05$; unpaired $t$-test), in comparison to the LMV $7.4_{\text {in }}$ formulation.

partitioning of dibucaine in solid lipid nanoparticles (Barbosa et al., 2013b). Nevertheless, the zeta potentials were high for the majority of the formulations, as desired for stable formulations, due to charge repulsion on the surfaces of the particles (Mohanraj \& Chen, 2006).

The extruded vesicles (LUV) showed diameters $(400-600 \mathrm{~nm})$ in the range of the polycarbonate membranes that did not change significantly in the presence of RVC. The polydispersion (PDI) values were uniform and small, at $\sim 0.2$, and increased to 0.3 after RVC addition. De Araújo et al. (2008) also prepared egg PC/chol/ $\alpha$-tocopherol (4:3:0.07 molar ratio) LUV at $\mathrm{pH} 7.4$, with no ionic gradient, and found vesicles with similar average diameters $(371 \pm 9.9 \mathrm{~nm}$, or $356 \pm 8.3 \mathrm{~nm}$ after RVC addition) and PDIs (0.12-0.17), reflecting the homogeneous distribution of the liposomal population obtained by extrusion.

The liposomes submitted to the freeze-thaw/agitation process (LMVV) presented $\mathrm{PDI}<0.8$ and particle size $(250-900 \mathrm{~nm})$ values that were higher than for LUV, but lower than for LMV (Table 3). The greater dimensions of the LMVVs were consistent with the results reported by Grant et al. (2004) for hydrogenated soy phosphatidylcholine (HSPC)/chol (2:1 molar ratio) vesicles, for which the average size was $2439 \pm 544 \mathrm{~nm}$.

\section{Transmission electron microscopy}

The TEM images revealed differences in the morphology of the prepared liposomes (Figure 3). LUV are regular, homogeneous, spherical-shaped vesicles (Cereda et al., 2013; Franz-Montan et al., 2013, 2015) with diameters of around $400 \mathrm{~nm}$, as shown by the results of the dynamic light scattering measurements (Table 3). LMVVs, prepared by extrusion and the freeze-thaw process, are large vesicles that can include nonconcentric lamellae and different particle sizes, as previously shown for LMVV with an ammonium sulfate gradient (Cohen et al., 2012). These oligomeric vesicles are less uniform, compared to LUV (Figure 3). The LMV (Figure 3A and B) consisted of concentric LMVs with the greatest diameters, in agreement with the light scattering results (Table 3). No morphology changes were detected for any of the three types of vesicle after addition of the anesthetic.

\section{Encapsulation efficiency}

Table 3 provides the RVC encapsulation efficiencies of the LMV, LMVV and LUV liposomes with different ionic gradients. In the case of the LMVs, the combined sulfate and $\mathrm{pH}$ gradient liposomes (LMV 5.5 in + ammonium sulfate) showed the highest $\mathrm{EE}(\%)(22.5 \pm 0.5)$, which was significantly higher than that of the conventional liposomes without gradient (LMV 7.4 in $_{\text {n }}$ ), in agreement with previous findings (Grant et al., 2004; Mowat et al., 1996).

The EE(\%) values obtained for the LUV were slightly higher than those obtained for the LMV formulations (Table 3). However, none of the ionic gradients provided any significant improvement in the encapsulation efficiency of RVC, compared to the conventional liposomes (LUV 7.4 $4_{\text {in }}$ ). The encapsulation efficiency determined for the LUV, without gradient, was in accordance with previous work that reported an $\mathrm{EE}(\%)$ value of $23.8 \pm 3.5 \%$ (de Araújo et al., 2008).

The best results were obtained with the LMVV formulations $(\mathrm{EE}(\%)=63-79.8)$, irrespective of whether any gradient was used. These findings were in agreement with the work of Grant et al. (2004), who encapsulated BVC in HSPC/chol (LMVV) liposomes and attributed the increased upload capacity of these oligolamellar vesicles to their large aqueous inner compartments. In light of this, it is possible that a strong contribution of the aqueous LMVV core could act to mask the effects of different ionic gradients on the encapsulation of RVC in LMVV.

\section{In vitro release assays}

Different liposomes (LMV, LMVV and LUV) were prepared with the same composition but with varying ionic gradients ( $\mathrm{pH}$ and salt) to create the driving forces required to actively upload and retain high amounts of protonated RVC inside the vesicles (Gubernator, 2011). The presence of an acid $\mathrm{pH}$ 

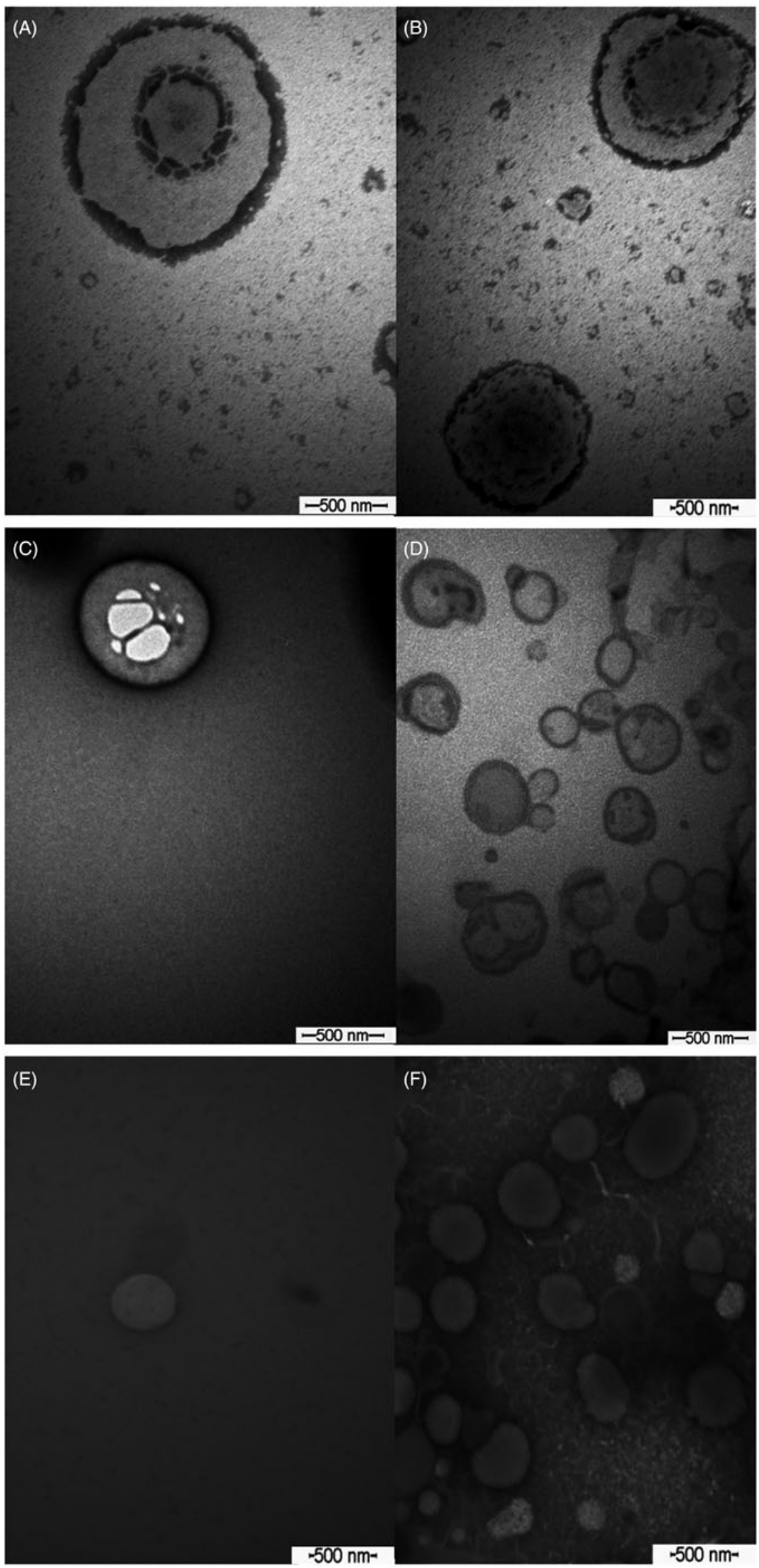

Figure 3. TEM micrographs of egg PC/chol/ $\alpha$-tocopherol (4:3:0.07 molar ratio) liposomes: LMV (A, B), LMVV (C, D) and LUV (E, F), stained with $2 \%$ uranyl acetate. The grids were evaluated under TEM at $80 \mathrm{kV}$. 

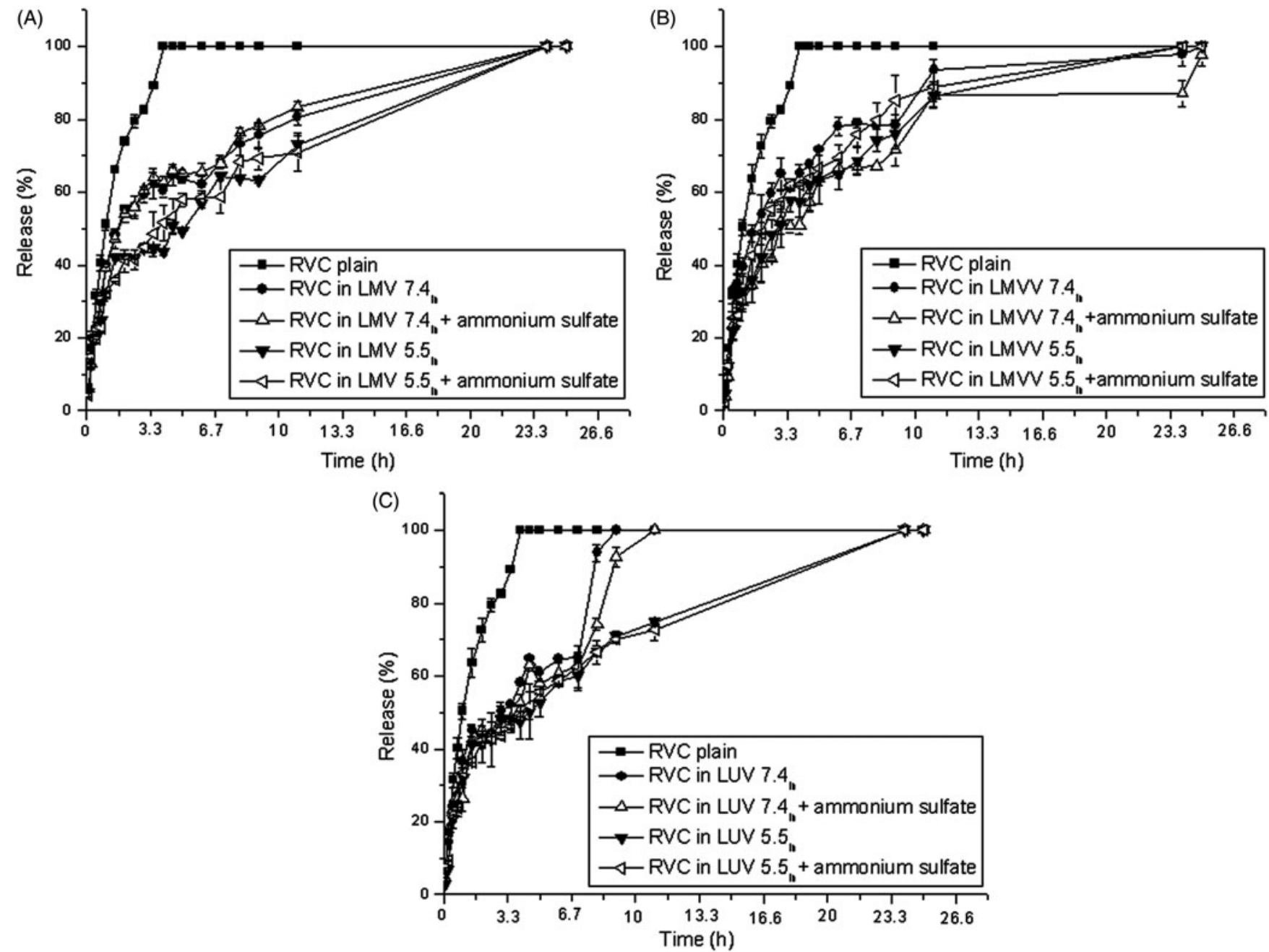

Figure 4. Release kinetics of RVC in solution ( $50 \mathrm{mM}$ Hepes buffer, $\mathrm{pH}$ 7.4) and encapsulated in the egg PC/chol/ $\alpha$-tocopherol (4:3:0.07 molar ratio)

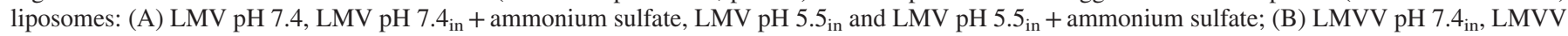

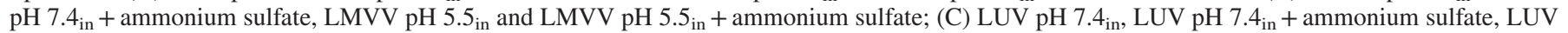
$\mathrm{pH} 5.5_{\text {in }}$ and LUV pH $5.5_{\text {in }}+$ ammonium sulfate.

inside the vesicles, or the encapsulation of $\left(\mathrm{NH}_{4}\right)_{2} \mathrm{SO}_{4}$, provided a "cage" for the anesthetic, in an approach known as the remote loading technique (Grant et al., 2004). In the case of the salt, ammonia (from the equilibrium $\mathrm{NH}_{4} \leftrightarrow \mathrm{NH}_{3}+\mathrm{H}^{+}$) leaves the vesicle, creating an ionic gradient by reducing the $\mathrm{pH}$ within the vesicles. In both cases, protonated RVC (which has high aqueous solubility) predominates at acidic $\mathrm{pH}$. In addition, in sulfate gradient liposomes, it is expected that the presence of $\mathrm{SO}_{4}^{2-}$ (counterions of $\mathrm{RVC}^{+}$) will further hinder passage of the anesthetic through the lipid bilayer. This type of delivery system should help to sustain the release of the anesthetic, providing longterm analgesia and reducing the systemic toxicity of the drug (de Paula et al., 2012).

The in vitro release time was determined for RVC in solution or encapsulated in the liposomes. The hyperbolic curves obtained (Figure 4) showed that $100 \%$ of RVC in solution was released after $4 \mathrm{~h}$, in agreement with previous observations (de Araújo et al., 2008). When RVC was encapsulated in the liposomal formulations (LMV, LMVV or LUV), with or without ionic gradients, $100 \%$ release was attained between 9 and $25 \mathrm{~h}$, indicating that all the liposomes tested were good carrier systems for the anesthetic. Table 4 provides the times for 50\% and total RVC release, together with the total areas under the curves.

The LMV delayed the release of RVC to around $24 \mathrm{~h}$ (Figure 4A, Table 4). The times required for $50 \%$ release $\left(t_{50 \%}\right)$ revealed that ionic gradients, especially LMV $5.5_{\text {in }}$ $\left(t_{50 \%}=4.6 \mathrm{~h}\right)$ and LMV $5.5_{\text {in }}+$ ammonium sulfate $\left(t_{50 \%}=3.6 \mathrm{~h}\right)$, retarded RVC diffusion, compared to conventional liposomes (LMV 7.4 in $; t_{50 \%}=1.7 \mathrm{~h}$ ), although no differences among the gradient formulations were detected when the AUC values (100\% release) were considered.

Once again, the oligolamellar vesicles showed better performance, compared to LMV and LUV (Figure 4B, Table 4). In the case of the LMVV formulations, the $t_{50 \%}$ values were always larger when ionic gradients were used, compared to LMVV 7.4 in (without ionic gradient). When the AUC values were compared, only the LMVV 7.4 in $_{\text {+ ammo- }}$ nium sulfate liposomes significantly retarded RVC release, compared to LMVV 7.4 in. Although the LMVV 5.5 in formulation also showed a good release profile, there was no significant difference compared to the conventional 
Table 4. Statistical analysis of the release kinetics of RVC in solution (50 mM Hepes buffer, pH 7.4) or encapsulated in egg $\mathrm{PC} / \mathrm{chol} / \alpha$-tocopherol (4:3:0.07 molar ratio) liposomes.

\begin{tabular}{|c|c|c|c|}
\hline Formulation & Release time (h) $50 \%$ & Release time (h) $100 \%$ & $\mathrm{AUC} \pm \mathrm{SD}(100 \%)$ \\
\hline RVC plain & 1.0 & 4.0 & $32932.7 \pm 259.1$ \\
\hline RVC in LMV $7.4_{\text {in }}$ & 1.7 & 23.9 & $110092.3 \pm 3755.4^{\mathrm{a}}$ \\
\hline RVC in LMV $7.4_{\text {in }}+$ ammonium sulfate & 1.7 & 23.9 & $113300.6 \pm 779.8^{\mathrm{a}}$ \\
\hline RVC in LMV $5.5_{\text {in }}$ & 4.6 & 23.9 & $101958.5 \pm 972.0^{\mathrm{a}}$ \\
\hline RVC in LMV $5.5_{\text {in }}+$ ammonium sulfate & 3.6 & 23.9 & $101967.8 \pm 5743.8^{\mathrm{a}}$ \\
\hline RVC in LMVV $7.4_{\text {in }}$ & 1.5 & 25.0 & $124423.3 \pm 1702.5^{\mathrm{a}}$ \\
\hline RVC in LMVV $7.4_{\text {in }}+$ ammonium sulfate & 3.0 & 25.0 & $131520.2 \pm 4085.3^{\mathrm{a}, \mathrm{b}}$ \\
\hline RVC in LMVV $5.5_{\text {in }}$ & 2.6 & 25.0 & $112348.8 \pm 4146.5^{\mathrm{a}}$ \\
\hline RVC in LMVV $5.5_{\text {in }}+$ ammonium sulfate & 2.1 & 24.1 & $116568.3 \pm 4243.2^{\mathrm{a}}$ \\
\hline RVC in LUV $7.4_{\text {in }}$ & 3.0 & 9.0 & $31645.0 \pm 417.1$ \\
\hline RVC in LUV $7.4_{\text {in }}+$ ammonium sulfate & 3.5 & 11.0 & $40546.6 \pm 1080.7^{\mathrm{a}, \mathrm{c}}$ \\
\hline RVC in LUV $5.5_{\text {in }}$ & 4.3 & 23.9 & $103523.0 \pm 1682.3^{\mathrm{a}, \mathrm{c}}$ \\
\hline RVC in LUV $5.5_{\text {in }}+$ ammonium sulfate & 4.3 & 23.9 & $102704.1 \pm 2089.6^{\mathrm{a}, \mathrm{c}}$ \\
\hline
\end{tabular}

AUC, area under the curve.

${ }^{a}$ Analysis of statistically significant differences (one-way ANOVA/Tukey-Kramer test, $p<0.05$ ): liposomal formulation versus RVC in solution.

${ }^{\mathrm{b}}$ Analysis of statistically significant differences (one-way ANOVA/Tukey-Kramer test, $p<0.05$ ): liposomal formulation versus RVC in LMVV 7.4 in $_{\text {. }}$.

${ }^{\mathrm{c}}$ Analysis of statistically significant differences (one-way ANOVA/Tukey-Kramer test, $p<0.05$ ): liposomal formulation versus RVC in LUV 7.4 in.

formulation, considering the areas under the curves. As discussed earlier for the $\mathrm{EE}(\%)$ values, the advantages provided by the liposome type (LMVV with greater internal aqueous volume) appear to have masked the effect of the different gradients tested.

The LUV vesicles without gradient showed faster release (100\% RVC release in 9h), compared to LMV and LMVV, probably due to the presence of a barrier consisting of a single bilayer. This was in agreement with the value of $7 \mathrm{~h}$ reported by de Araújo et al. (2008). All the ionic gradients acted to delay RVC release from the liposomes. The use of LUV $7.4_{\text {in }}+$ ammonium sulfate $\left(t_{50 \%}=3.5 \mathrm{~h}\right)$ resulted in an increase in the total release time to $11 \mathrm{~h}$. The LUV $5.5_{\text {in }}$ $\left(t_{50 \%}=4.3 \mathrm{~h}\right)$ and LUV $5.5_{\mathrm{in}}+$ ammonium sulfate $\left(t_{50 \%}=4.3 \mathrm{~h}\right)$ gradient formulations also provided more gradual release of the anesthetic ( $100 \%$ release after $23.9 \mathrm{~h})$, once again showing that the presence of a gradient acted to extend the duration of RVC release.

Mowat et al. (1996) investigated LUV composed of dioleoyl $\mathrm{PC} /$ chol at $\mathrm{pH}$ 7.4, prepared with a $\mathrm{pH}$ gradient ( $\mathrm{pH} 4.0$ inside), and reported that only $40 \%$ of BVC was released from the liposomes after $24 \mathrm{~h}$. When tested in vivo, the formulation provided $\sim 14 \mathrm{~h}$ of nerve block in guinea pigs, compared to $7 \mathrm{~h}$ for a conventional liposome formulation. Grant et al. (2004) prepared HSPC/chol LMVV with a $250 \mathrm{mM}$ ammonium sulfate gradient for the encapsulation of BVC, and reported long anesthesia times after intradermal administration in humans: 19,38 and $48 \mathrm{~h}$, for $0.5 \%$, $1 \%$ and $2 \%$ BVC, respectively. Although the lipophilicity of BVC is higher than that of RVC, these two anesthetics have many similar properties. Considering the excellent in vivo results that have been reported previously for BVC, together with the good in vitro results obtained in this study, the use of ionic gradient liposomes with these types of LAs (especially RVC) appears to offer new options for drug delivery to control pain during surgery and the postoperative period.

\section{Conclusions}

Liposomal formulations with different vesicle types (multilamellar, multivesicular and unilamellar) were successfully prepared at $\mathrm{pH}$ 7.4. The novelty of this work is that the formulations were prepared with ionic gradients $\left(\mathrm{pH} 5.5_{\text {in }}\right.$ and/or ammonium sulfate inside) in order to upload high amounts of RVC. EPR analysis revealed that egg PC/chol/ $\alpha$-tocopherol (4:3:0.07 molar ratio) liposomes presented low fluidity, which enabled the ionic gradient to be maintained for a prolonged period, resulting in sustained release of the anesthetic.

Among the liposome types tested, multivesicular liposomes showed the highest encapsulation efficiency $(\sim 70 \%)$ and sustained release $(25 \mathrm{~h})$, probably due to the presence of large aqueous spaces into which RVC was efficiently uploaded. The remote loading of liposomes approach proved to be very useful, with both $\mathrm{pH}$ and $\left(\mathrm{NH}_{4}\right)_{2} \mathrm{SO}_{4}$ gradients providing similar increases in the sustained release of RVC, compared to conventional liposomes without gradi-

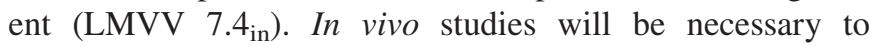
evaluate the therapeutic effects of these formulations.

\section{Declaration of interest}

The authors acknowledge the financial support received (grant \#2011/21735-3) from the São Paulo Research Foundation (FAPESP, Brazil). The authors declare that there are no conflicts of interest.

\section{References}

Barbosa RM, da Silva CMG, Bella TS, et al. (2013a). Cytotoxicity of solid lipid nanoparticles and nanostructured lipid carriers containing the local anesthetic dibucaine designed for topical application. J Phys Conf Ser 429:1-8.

Barbosa RM, Klassen A, Marcato PD, et al. (2013b). Validation of an HPLC method for the determination of dibucaine encapsulated in solid lipid nanoparticles and nanostructured lipid carriers. Lat Am J Pharm 32:1362-9. 
Barenholz Y, Haran G. (1993). Method of amphiphatic drug loading in liposomes by pH gradient. US Patent \# 5, 192, 549.

Barenholz Y, Haran G. (1994). Method of amphiphatic drug loading in liposomes by ammonium ion gradient. US Patent \# 5, 316, 771.

Boogaerts JG, Lafond ND, Declercq AG, et al. (1994). Epidural administration of liposome-associated bupivacaine for the management of postsurgical pain: a first study. J Clin Anesth 6:315-20.

Boogaerts J, Lafont N, Donnay M, et al. (1995). Motor blockade and absence of local nerve toxicity induced by liposomal bupivacaine injected into the brachial plexus of rabbits. Acta Anaesthesiol Belg 46: $19-24$.

Catterall W, Mackie K. (2011). Local anesthetics. In: Goodman LS, Gilman AG, eds. The pharmacological basis of therapeutics. New York: McGraw-Hill, 1732-4.

Celano M, Calvagno MG, Bullota S, et al. (2004). Cytotoxic effects of gemcitabine-loaded liposomes in human anaplastic thyroid carcinoma cells. BMC Cancer 4:1-5.

Cereda CM, Brunetto GB, Araújo DR, de Paula E. (2006). Liposomal formulations of prilocaine, lidocaine and mepivacaine prolong analgesia duration. Can J Anaesth 53:1092-7.

Cereda CM, de Araújo DR, Brunetto GB, de Paula E. (2004). Liposomal prilocaine: preparation, characterization and in vivo evaluation. J Pharm Pharm Sci 7:235-40.

Cereda CM, Franz-Montan M, Silva CMG, et al. (2013). Transdermal delivery of butamben from elastic and conventional liposomes. J Liposome Res 23:228-34.

Cern A, Golbraikh A, Sedykh A, et al. (2012). Quantitative structureproperty relationship modeling of remote liposome loading of drugs. J Control Release 160:147-57.

Chen PS, Toribara Jr TY, Warner H. (1956). Microdetermination of phosphorus. Anal Chem 28:1756-8.

Cohen R, Kanaan H, Grant GJ, Barenholz Y. (2012). Prolonged analgesia from bupisome and bupigel formulations: from design and fabrication to improved stability. J Control Release 160:346-52.

Davidson EM, Barenholz Y, Cohen R, et al. (2010). High-dose bupivacaine remotely loaded into multivesicular liposomes demonstrates slow drug release without systemic toxic plasma concentrations after subcutaneous administration in humans. Anesth Analg 110: 1018-23.

de Araújo DR, Cereda CM, Brunetto GB, et al. (2004). Encapsulation of mepivacaine prolongs the analgesia provided by sciatic nerve blockade in mice. Can J Anaesth 51:566-72.

de Araújo DR, Cereda CM, Brunetto GB, et al. (2008). Pharmacological and local toxicity studies of a liposomal formulation for the novel local anaesthetic ropivacaine. J Pharm Pharmacol 60:1449-57.

de Paula E, Cereda CM, Fraceto LF, et al. (2012). Micro and nanosystems for delivering local anesthetics. Expert Opin Drug Deliv 9:1505-24.

de Paula E, Cereda CM, Tofoli GR, et al. (2010). Drug delivery systems for local anesthetics. Recent Pat Drug Deliv Formul 4:23-34.

de Paula E, Schreier S. (1995). Use of a novel method for determination of partition coefficients to compare the effect of local anesthetics on membrane structure. Biochim Biophys Acta 1240:25-33.

Franz-Montan M, Baroni D, Brunetto G, et al. (2015). Liposomal lidocaine gel for topical use at the oral mucosa: characterization, in vitro assays and in vivo anesthetic efficacy in humans. J Liposome Res 25:11-19.

Franz-Montan M, Cereda CM, Gaspari A, et al. (2013). Liposomalbenzocaine gel formulation: correlation between in vitro assays and in vivo topical anesthesia in volunteers. J Liposome Res 23:54-60.

Franz-Montan M, Silva ALR, Cogo K, et al. (2007). Liposomeencapsulated ropivacaine for topical anesthesia in human oral mucosa. Anesth Analg 104:1528-31.

Gesztes A, Mezei M. (1988). Topical anesthesia of the skin by liposomeencapsulated tetracaine. Anesth Analg 67:1079-81.

Grant SA. (2002). The holy grail: long-acting local anesthetics and liposomes. Best Pract Res Clin Anesthesiol 16:345-52.
Grant GJ, Bansinath M. (2001). Liposomal delivery systems for local anesthetics. Reg Anesth Pain Med 26:61-3.

Grant GJ, Barenholtz Y, Bolotin E, et al. (2004). A novel liposomal bupivacaine formulation to produce ultralong-acting analgesia. Anesthesiology 101:133-7.

Grant GJ, Barenholtz Y, Piskoun B, et al. (2001). DRV liposomal bupivacaine: preparation, characterization, and in vivo evaluation in mice. Pharm Res 18:336-43.

Grant GJ, Lax J, Susser L, et al. (1997). Wound infiltration with liposomal bupivacaine prolongs analgesia in rats. Acta Anaesthesiol Scand 41:204-7.

Grant GJ, Vermeulen K, Langerman L, et al. (1994). Prolonged analgesia with liposomal bupivacaine in a mouse model. Reg Anesth 19:264-9.

Griffith OH, Jost OP. (1976). Spin labels in biological membranes. In: Berliner LJ, ed. Spin labeling: theory and applications. New York: Academic Press, 454-523.

Grillo R, Melo NFS, de Araújo DR, et al. (2009). Validation of an HPLC method for quantitative determination of benzocaine in PHBV microparticles and PLA-nanoparticles. Lat Am J Pharm 28:393-9.

Gubernator J. (2011). Active methods of drug loading into liposomes: recent strategies for stable drug entrapment and increased in vivo activity. Expert Opin Drug Deliv 8:565-80.

ICH. (2005). Validation of analytical procedures: text and methodology (Q2R1). International Conference on Harmonization; Nov 2005; Geneva.

Jonsson JA, Andersson M, Melander C, et al. (2000). Automated liquid membrane extraction for high-performance liquid chromatography of ropivacaine metabolites in urine. J Chromatogr A 870:151-7.

Lafont ND, Legros FJ, Boogaerts JG. (1996). Use of liposome-associated bupivacaine in a cancer pain syndrome. Anaesthesia 51:578-9.

Lagan G, McLure HA. (2004). Review of local anaesthetic agents. Curr Anaesth Crit Care 15:247-54.

Mohanraj VJ, Chen Y. (2006). Nanoparticles - a review. Trop J Pharm Res 5:561-73.

Mowat JJ, Mok MJ, MacLeod BA, Madden TD. (1996). Liposomal bupivacaine extended duration nerve blockade using large unilamellar vesicles that exhibit a proton gradient. Anesthesiology 85:635-43.

Pinto LMA, Yokaichiya DK, Fraceto LF, de Paula E. (2000). Interaction of benzocaine with biomembranes. Biophys Chem 87:213-23.

Samad A, Sultana Y, Aqil M. (2007). Liposomal drug delivery systems: an update review. Curr Drug Deliv 4:297-305.

Schreier S, Polnaszek CF, Smith IC. (1978). Spin labels in membranes. Problems in practice. Biochim Biophys Acta 515:395-436.

Strichartz GR, Covino BG. (1990). Local anesthetics. In: Miller RD, ed. Anesthesia. New York: Churchill Livingstone, 437-70.

Torchilin VP. (2005). Recent advances with liposomes as pharmaceutical carriers. Nat Rev Drug Discov 4:145-60.

Torchilin VP. (2012). Liposomes in drug delivery. Adv Deliv Sci Technol 4:289-328.

Tu S, McGinnis T, Krugner-Higby L, Heath TD. (2010). A mathematical relationship for hydromorphone loading into liposomes with transmembrane ammonium sulfate gradients. J Pharm Sci 99:2672-80.

Warren RC. (1987). Physics and architecture of cell membranes. Bristol and Philadelphia (PA): Adam-Hilger.

Weiniger CF, Golovanevski M, Sokolsky-Papkov M, Domb AJ. (2010). Review of prolonged local anesthetic action. Exp Opin Drug Deliv 7: 737-52.

Wiles MD, Nathanson MH. (2010). Local anaesthetics and adjuvants future developments. Anaesthesia 65:22-37.

Yu HY, Li SD, Sun P. (2002). Kinetic and dynamic studies of liposomal bupivacaine and bupivacaine solution after subcutaneous injection in rats. J Pharm Pharmacol 54:1221-7.

Zuo M, Duan GL, Ge ZG. (2004). Simultaneous determination of ropivacaine and antipyrine by high performance liquid chromatography and its application to the in vitro transplacental study. Biomed Chromatogr 18:752-5. 